Short Communication

\title{
Synthesis of a Highly Porous Nitrogen-Doped Carbon Material from a Melamine/Formaldehyde Resin with Potassium Citrate
}

\author{
Wei Xiong, Ji Hoon Kang, Jin Kyeong Kang, and Yongju Jung* \\ Department of Chemical Engineering, Korea University of Technology and Education \\ (KOREATECH), Cheonan, 330-780, Korea \\ *E-mail: yjung@koreatech.ac.kr
}

doi: $10.20964 / 2017.10 .69$

Received: 3 July 2017 / Accepted: 12 August 2017 / Published: 12 September 2017

\begin{abstract}
Nitrogen-doped porous carbons were synthesized from an aqueous solution of melamine and formaldehyde. The addition of potassium citrate to the solution mixture led to a tremendous increase in the surface area from $74 \mathrm{~m}^{2} / \mathrm{g}$ to $2718 \mathrm{~m}^{2} / \mathrm{g}$, indicating that potassium citrate served as an excellent pore former. The nitrogen-doped carbon exhibited remarkable capacitive performance, such as a high capacitance of $320 \mathrm{~F} / \mathrm{g}$ at $0.1 \mathrm{~A} / \mathrm{g}$, an excellent rate capability $(70 \%$ at $10.0 \mathrm{~A} / \mathrm{g})$, and a high cycling stability $(94.6 \%$ retention after 2000 cycles) in $6.0 \mathrm{M} \mathrm{KOH}$ aqueous solution. Furthermore, the nitrogen-doped carbon delivered a high energy density of $7.8 \mathrm{Wh} / \mathrm{kg}$ even at a high power density of $5000 \mathrm{~W} / \mathrm{kg}$. We believe that the synthesis strategy presented in this work could be used as a promising way to fabricate electrode materials for high-performance supercapacitors.
\end{abstract}

Keywords: Melamine, Formaldehyde, Potassium Citrate, N-doped Porous Carbon

\section{$\underline{\text { FULL TEXT }}$}

(C) 2017 The Authors. Published by ESG (www.electrochemsci.org). This article is an open access article distributed under the terms and conditions of the Creative Commons Attribution license (http://creativecommons.org/licenses/by/4.0/). 